UDC 612.115+ [616.39:616.37-008.64]:616-092.9

doi: https://doi.org/10.15407/ubj90.02.014

\title{
BLOOD COAGULATION AND AORTIC WALL INTEGRITY IN RATS WITH OBESITY-INDUCED INSULIN RESISTANCE
}

\author{
O. S. DZIUBA ${ }^{1 凶}$, V. O. CHERNYSHENKOㄹ, Ie. A. HUDZ ${ }^{1}$, \\ L. O. KASATKINA', T. M. CHERNYSHENKO ${ }^{1}$, P. P. KLYMENKO', \\ H. V. KOSIAKOVA' ${ }^{1}$, T. M. PLATONOVA ${ }^{1}$, N. M. HULA ${ }^{1}$, E. V. LUGOVSKOY ${ }^{1}$ \\ ${ }^{1}$ Palladin Institute of Biochemistry, National Academy of Sciences of Ukraine, Kyiv; \\ ৫e-mail: oksana.dziuba86@gmail.com; \\ ${ }^{2}$ State Institute of Gerontology of AMS of Ukraine, Kyiv
}

\begin{abstract}
Obesity is an important factor in pathogenesis of disorders caused by chronic inflammation. Diet-induced obesity leads to dyslipidemia and insulin resistance (IR) that in turn provoke the development of type 2 diabetes and cardiovascular diseases. Thus, the aim of this work was to investigate the possible pro-atherogenic effects in the blood coagulation system and aortic wall of rats with obesity-induced IR. The experimental model was induced by a 6-month high-fat diet (HFD) in white rats. Blood samples were collected from 7 control and 14 obese IR rats. Prothrombin time (PT) and partial activated thromboplastin time (APTT) were performed by standard methods using Coagulometer Solar CT 2410. Fibrinogen concentration in the blood plasma was determined by the modified spectrophotometric method. Levels of protein C (PC), prothrombin and factor $X$ were measured using specific chromogenic substrates and activating enzymes from snake venoms. Platelet aggregation was measured and their count determined using Aggregometer Solar AP2110. The aorta samples were stained by hematoxylin and eosin according to Ehrlich. Aortic wall thickness was measured using morphometric program Image J. Statistical analysis was performed using Mann-Whitney U Test. The haemostasis system was characterized by estimation of the levels of individual coagulation factors, anticoagulant system involvement and platelet reactivity. PT and APTT demonstrated that blood coagulation time strongly tended to decrease in obese IR rats in comparison to the control group. It was also detected that 30\% of studied obese IR rats had decreased factor X level, $40 \%$ had decreased level of prothrombin whereas fibrinogen concentration was slightly increased up to $3 \mathrm{mg} / \mathrm{ml}$ in $37 \%$ of obese IR rats. A prominent decrease of anticoagulant PC in blood plasma of obese rats was detected. Obese IR rats also had increased platelet count and higher rate of platelet aggregation in comparison to control animals. Histological analysis identified the disruption of aorta endothelium and tendency for the thickening of the aorta wall in the group with obesityinduced IR compared to the group of control rats. Changes of individual coagulation factors were assumed as the evidence of imbalance in the blood coagulation system. Increase of fibrinogen level, drop in PC concentration and pathological platelet reactivity were taken to corroborate the development of low-grade inflammation in obese IR rats. Instant generation of small amounts of thrombin in their blood plasma is expected. Since the aorta morphology assay detected the trend of its wall to thicken and the emergence of disruptions, we assumed there were initial stages of atherosclerosis and the danger of developing atherothrombosis. We detected an increase of blood coagulability and changes in aorta morphology in rats with obesity-induced IR which we assume indicate early development of atherosclerosis.
\end{abstract}

Keywords: obesity, atherosclerosis, insulin resistance, haemostasis, fibrinogen, blood coagulation, inflammation.

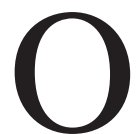
besity is recognized as an important factor in the pathogenesis of metabolic disorders. Metabolic syndrome which is related to weight gain, specifically intra-abdominal fat ac- cumulation, is a known risk factor for early cardiovascular diseases. The reason for such a dependence is clear from the other name for the metabolic syndrome; it is also known as 'the deadly quartet'

(C) 2018 Dziuba O. S. et al. This is an open-access article distributed under the terms of the Creative Commons Attribution License, which permits unrestricted use, distribution, and reproduction in any medium, provided the original author and source are credited. 
because it includes obesity, insulin resistance, hypertension, and dyslipidemia. All these factors predispose to serious complications, particularly atherosclerosis and consequent cardiovascular disease $[1,2]$.

Atherosclerosis is a disease characterized by plaque formation in the arterial wall [3]. According to 'the response to injury' theory, the earliest event in atherogenesis is injury of the endothelium caused by blood turbulence (for example, during hypertension), direct physical or chemical injury, oxidative stress, etc [4]. Atherosclerotic plaques consist of vascular smooth muscle cells, inflammatory macrophages, foam cells, dysfunctional endothelium, extracellular lipids, collagen and blood proteins [5]. Of course for plaques to form, components of the extracellular matrix, collagen and activated macrophages in the bloodstream have to initiate local blood clotting activation, platelet aggregation and fibrin formation [6-8].

The strong dependence of atherogenesis on blood coagulation has been known for many years [9]. Still, in many recent works the role of haemostasis imbalance in atherosclerosis development is omitted $[10,11]$ despite several reports about the insufficiency of a theory that postulates the exceptional role of cholesterol in atherosclerotic plaque formation [12-14].

Haemostasis has an essential role in protecting vascular integrity and maintaining normal blood flow. According to our recent knowledge, the coordination of inflammation and haemostasis and haemostatic response to inflammation are the crucial mechanisms of haemostasis linkage to the pathophysiology of atherogenesis [15]. H. ten Cate and co-authors in several studies demonstrated the co-localisation of early atherosclerotic plaques and functional activity of many coagulation proteins, including factor Xa and mainly thrombin [16-18].

The main goal of this work was to investigate the possible proatherogenic effects in the artery wall and blood coagulation system of obese insulin-resistant rats.

\section{Materials and Methods}

Blood sampling. Samples of rat blood were collected by heart puncture. 3.8\% sodium citrate was added to blood immediately after collection. Plateletrich plasma (PRP) was prepared from citrated blood by centrifugation at $1000 \mathrm{rpm}$ for $30 \mathrm{~min}$. Platelet poor plasma (PPP) was obtained from PRP by cen- trifugation of PRP for $15 \mathrm{~min}$ at $1500 \mathrm{rpm}$. This study was approved by the Animal Care and Use Committee of the Palladin Institute of Biochemistry, National Academy of Sciences of Ukraine (Protocol N1 from 08/09-2015).

Reagents. Chromogenic substrates S2238 (HD-Phe-Pip-Arg-pNA), S2765 (Z-D-Arg-Gly-ArgpNA) and S2236 (p-Glu-Pro-Arg-pNa) were purchased from BIOPHEN (Neuville-sur-Oise, France), APTT-reagent, thromboplastin and protein C (PC) activator were from Renam (Moscow, Russia). Ecamulin was purified from Echis multisquamatis venom according to the method of Solov'yev et al [19]. Factor X activator from Daboia russellii venom (RVV) and ADP were purchased from SigmaAldrich (St. Louis, USA).

Animal model. White outbred male rats with body weight $170 \pm 4 \mathrm{~g}$ were used. Animals were kept in standard cages with free access to food and water in accordance with General Ethical Principles of Experiments on Animals (Ukraine, 2001), which are consistent with the provisions of "The European Convention for the Protection of Vertebrate Animals Used for Experimental and Other Scientific Purposes” (Strasbourg, 1986). This study was carried out with the approval of the Animal Care and Use Committee of the Palladin Institute of Biochemistry, National Academy of Sciences of Ukraine (Protocol N1 from 08/09-2015).

Insulin resistance (IR) of the model was induced by high-fat diet (HFD) containing $58 \%$ fats of the total diet for 6 months (September 2015 - March 2016). The control group received a standard pellet diet containing $4 \%$ fats. At the $24^{\text {th }}$ week, the body weight of HFD rats was $383 \pm 12 \mathrm{~g}$ compared to $279 \pm 7 \mathrm{~g}$ for control rats. The group of rats with obesity-induced IR was selected on the basis of the results of the oral glucose tolerance test [20] carried out after 24 weeks. The animals with the blood glucose level higher than $5 \mathrm{mmol} / \mathrm{l}$ after 150 minutes of glucose administration were selected as insulinresistant.

After 6 months of experiments, animals were decapitated under Nembutal anesthesia (dosage was $50 \mathrm{mg} / \mathrm{kg}$ of body weight) according to ethical standards and principles specified above. For further studies we collected samples of blood plasma and tissues from 7 healthy animals (control group) and 14 obese insulin-resistant rats (obese diabetic group).

Activated partial prothrombin time. Activated partial thromboplastin time (APTT) was performed 
according to the following procedure. $0.1 \mathrm{ml}$ of blood plasma was mixed with an equal volume of APTTreagent and incubated for 3 minutes at $37^{\circ} \mathrm{C}$. Then the coagulation was initiated by adding $0.1 \mathrm{ml}$ of $0.025 \mathrm{M}$ solution of $\mathrm{CaCl}_{2}$. Clotting time was monitored by the Coagulometer Solar CGL-2410 (Solar, Minsk, Belorussia).

Prothrombin time. Prothrombin time (PT) was measured by the Coagulometer Solar CGL-2410 (Belorussia). Clotting was initiated by mixing $0.1 \mathrm{ml}$ of blood plasma with $0.1 \mathrm{ml}$ of $0.025 \mathrm{M} \mathrm{CaCl}_{2}$ and $0.1 \mathrm{ml}$ of thromboplastin reagent (Renam, Moscow, Russia). Thromboplastin acts through the tissue factor pathway of coagulation and activates only carboxylated and uncleaved forms of prothrombin.

Factor X level. Factor X was activated directly in blood plasma by RVV [21]. Enzymatic activity of factor Xa was estimated with specific chromogenic substrate S2765 (Z-D-Arg-Gly-Arg-pNA). Substrate cleavage was monitored using the reader (Thermo Fisher Scientific, Waltham, USA). The analysis was performed in $0.05 \mathrm{M}$ Tris- $\mathrm{HCl}$ buffer $\mathrm{pH} 7.4$ solution, $37{ }^{\circ} \mathrm{C}$. Chromogenic substrate concentration was $30 \mathrm{mM}$.

Total prothrombin level. To determine total prothrombin level the ecamulin test was used. Ecamulin (prothrombin activator from Echis multisqumatis venom) is an enzyme that activates prothrombin, descarboxy-prothrombin and prethrombin 1. So activation by ecamulin allowed us to determine total prothrombin level [22]. Thrombin generation induced by ecamulin was measured by chromogenic substrate assay using thrombin-specific S2238 (HD-Phe-Pip-Arg-pNA) as previously described [23].

Fibrinogen concentration. Fibrinogen concentration in the blood plasma was determined by the modified spectrophotometric method. Blood plasma $(0.2 \mathrm{ml})$ and PBS $(1.7 \mathrm{ml})$ were mixed in glass tubes. Coagulation was initiated by the addition of $0.1 \mathrm{ml}$ of thrombin $(2 \mathrm{NIH} / \mathrm{ml})$. To avoid fibrin cross-linking $0.1 \mathrm{ml}$ of $40 \mathrm{mM}$ monoiodacetic acid was added to the sample. The mixture was incubated for $30 \mathrm{~min}$ at $37{ }^{\circ} \mathrm{C}$. The fibrin clot was removed and redissolved in $5 \mathrm{ml}$ of $1.5 \%$ acetic acid. The concentration of protein was measured using spectrophotometer Optizen POP (Mecacys, Seongnam, South Korea) at $280 \mathrm{~nm}(\varepsilon=1.5)$.

Protein $C$ level. PC level was determined using the activator of PC from Agkistrodon halys halys venom, as previously described [24]. The generation of activated PC was measured by chromogenic substrate assay using specific chromogenic substrate
S2236 (p-Glu-Pro-Arg-pNa). The analysis was done in $0.05 \mathrm{M}$ Tris- $\mathrm{HCl}$ buffer $\mathrm{pH} 7.4$, at $37^{\circ} \mathrm{C}$. Chromogenic substrate concentration was $30 \mathrm{mM}$.

Platelet aggregation. Platelet aggregation measurements were based on changes in the turbidity of human PRP [25]. Aggregation was registered for 10 min using Aggregometer Solar AP2110 (Solar, Minsk, Belorussia). Platelet count was estimated using the same device. We measured the initial rate and final level of aggregation at $37^{\circ} \mathrm{C}$. In a typical experiment $250 \mu \mathrm{l}$ of PRP was incubated with $\mathrm{CaCl}_{2}$ $(10 \mu \mathrm{M})$ activated by platelet agonist $\operatorname{ADP}(12.5 \mu \mathrm{M})$ at $37^{\circ} \mathrm{C}$.

Histology and aortic wall thickness measurement. Histological samples of the aorta for light-microscopic examination were prepared as previously described [26]. After decapitation, the fragment of aorta was isolated and fixed in $10 \%$ neutral formalin for 24 hours. Then it was dehydrated in ethanol of increasing concentrations (70, 80, 90 and 96\%) and the aortic fragment was embedded in paraffin. Sections of tissues $5 \mu \mathrm{m}$ thick were made on a microtome. The samples were stained by hematoxylin and eosin according to Ehrlich and by Mason-Goldner trichrome staining and studied by microscopy. Stained histological samples were studied using Olympus BX51 microscope (Olympus, Tokyo, Japan).

Aortic wall thickness was measured using morphometric program Image $J$ (National Institutes of Health, Maryland, USA).

Statistics. Statistical data analysis was performed using the Mann-Whitney $U$ test for independent groups in Microsoft Excel (Microsoft, Redmond, USA). All assays were replicated thrice. Results are presented as means \pm standard deviation. Data were considered significant when $P<0.05$.

\section{Results and Discussion}

Detection of obesity and insulin resistance in experimental groups of animals. Body weight and fasting blood glucose level of experimental animals were measured every month during HFD. The dynamics of the weight growth of the rats demonstrated a statistically significant difference between control and HFD groups at 2 months after the study began. Average monthly weight gains were $16 \%$ and $31 \%$ of output indicators for rats in the control group and HFD group respectively.

Impairment of glucose tolerance was observed in $89 \%$ of obese rats. This animal model of obesityinduced IR was thoroughly investigated in earlier studies and it was confirmed by the homeostatic 
model assessment (HOMA-IR) that IR strongly correlated with impaired glucose tolerance [27]. In our experiment the average blood glucose level at the end of testing was $6.67 \pm 0.185$ in HFD rats compared to $4.46 \pm 0.106$ in control rats.

As it has been shown before [28], the development of type 2 diabetes in the metabolic animal model is accompanied by low-grade inflammation which is characterized by increased TNF $\alpha$ accumulation as well as lipid imbalance, in particular in blood. These changes could be assumed as risk factors for atherosclerosis development.

Haemostasis parameters. Obesity and IR were shown for the experimental groups of animals. Both these conditions are important risk factors for cardiovascular complications and changes in haemostasis that could lead to atherosclerosis with subsequent thrombosis. Thus, our next goal was to characterize the haemostasis system of rats with obesity-induced IR. To achieve this goal we performed a number of tests that allowed us to determine the overall procoagulant potential and then estimate the levels of individual coagulation factors, platelet reactivity, anticoagulant system and fibrinolysis involvement.

Basic coagulation tests. Basic coagulation tests were performed for initial characterization of intrinsic and extrinsic pathways of the coagulation system [29] and for detection of overall procoagulant potential of haemostasis [30]. Normally, determination of these parameters is insufficient to characterize the haemostasis system and several additional tests are needed [31]. However, we were able to detect obvious differences in PT and APTT of control rats and obese IR rats. Fig. 1, $A$ demonstrates the tendency for the shortening of blood coagulation time in the PT test. The time of clotting initiated by thromboplastin is shortened. In other words, the prothrombin index (PI, often calculated in clinics) of obese diabetic rats decreased to $81 \pm 19 \%$ [32]. APTT of obese diabetic rats is shortened more clearly (Fig. 1, B).

In general, more than $50 \%$ of obese IR animals possessed increased coagulability of blood plasma detected using the basic coagulation tests APTT and PT. Such results are considered evidence of coagulation dysfunction but the origin of this has to be studied more precisely [33]. Nonetheless, the observed shortening in coagulation time in APTT and PT tests indicates the pre-activation of clotting and the risk of intravascular thrombus formation in obese insulin-resistant rats.

Individual coagulation factor levels. Blood coagulation cascade initiated by the intrinsic or extrinsic mechanism results in three main reactions: activation of factor $\mathrm{X}$ by tenase complex with generation of active factor $\mathrm{Xa}$; the latter being part of the prothrombinase complex that is then able to activate prothrombin with the generation of thrombin; thrombin then converts fibrinogen to fibrin that is
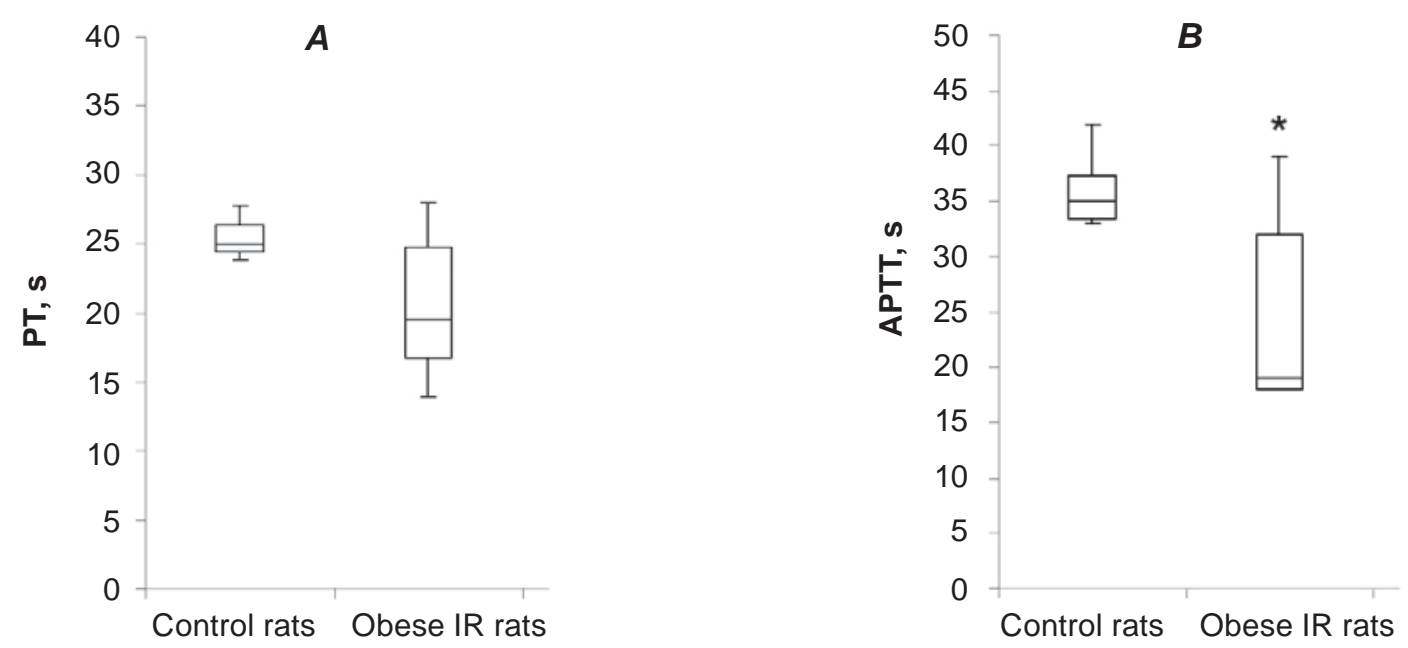

Fig. 1. Clotting time of blood plasma of control rats and obese insulin-resistant rats in basic coagulation tests. A. PT - prothrombin time. In this test blood clotting is initiated by thromboplastin (TF). It characterizes the extrinsic pathway of the coagulation system. B. APTT - activated partial thromboplastin time. This test primarily demonstrates the coagulant ability of the intrinsic pathway of the blood coagulation cascade ( $p=0.034$ according to Mann-Whitney U Test). IR, insulin resistance. *Statistically significant difference of means compared to control group, $P<0.05$ 

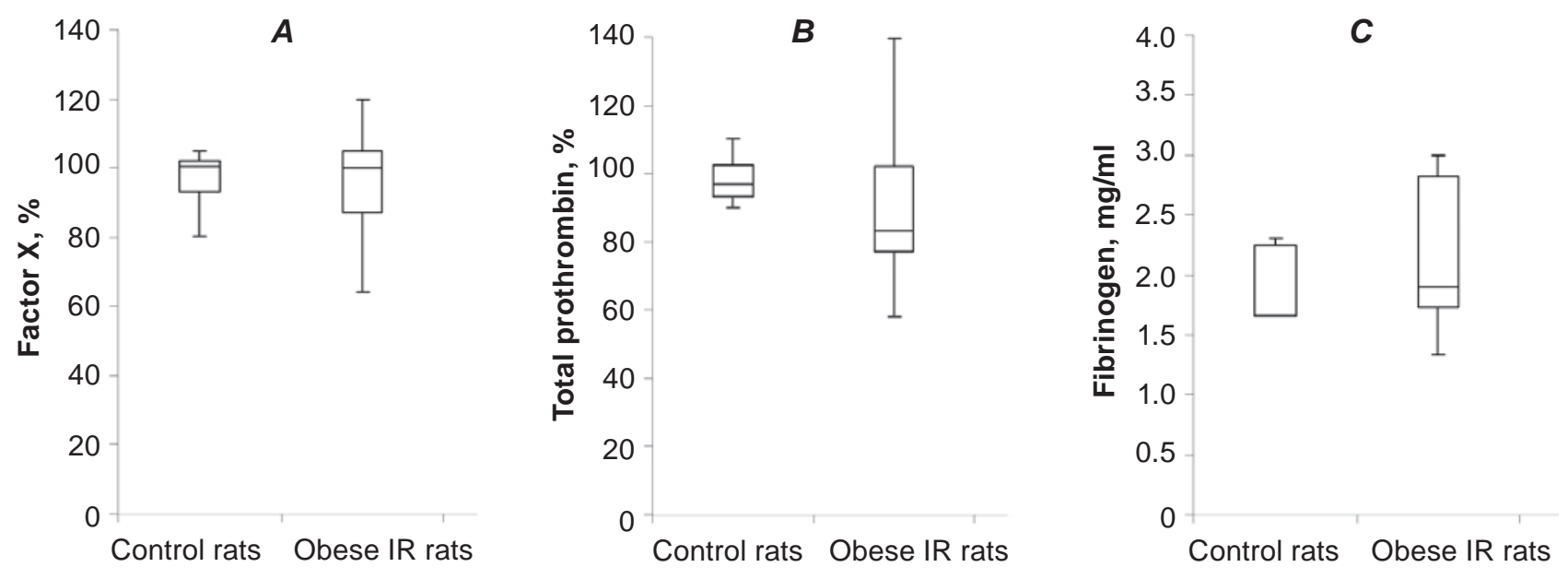

Fig. 2. Level of crucial coagulation factors in blood plasma of control rats and obese insulin-resistant rats. A. The level of total factor $X$ was measured using non-physiological activating enzyme from the venom of Daboia russellii (RVV) and factor Xa-specific chromogenic peptide substrate S2765 (Z-D-Arg-Gly-Arg-pNA).

$\boldsymbol{B}$. The total prothrombin level was measured using non-physiological activating enzyme from the venom of Echis multisquamatis (ecamulin) and thrombin-specific chromogenic peptide substrate S2238 (D-Phe-PipArg-pNA). C. The concentration of fibrinogen in blood plasma of control rats and obese diabetic rats, determined using modified spectrofluorometric method using thrombin-like enzyme from the venom of Agkistrodon halys halys

able to polymerize and to form a polymeric networklike core of a thrombus [34]. Thus, we determined the levels of factor X, prothrombin and fibrinogen in blood plasma of control rats and obese diabetic rats.

Surprisingly enough no statistically significant differences in these parameters were observed between studied groups (Fig. 2). However, as it can be seen by deviations of the parameters, the imbalance of the coagulation factor levels in blood plasma of obese insulin-resistant animals was obvious. In particular, $30 \%$ of studied obese insulin-resistant animals had decreased factor X level and $40 \%$ had decreased level of prothrombin. Fibrinogen concentration was slightly increased (up to $3 \mathrm{mg} / \mathrm{ml}$ ) in 37\% of animals. In the control group of rats it was not higher then $2.25 \mathrm{mg} / \mathrm{ml}$. The increasing fibrinogen concentration could be a consequence of low-grade inflammation [35]. The increase of the concentration of fibrinogen along with a tendency for accumulation of the main proenzymes of the blood coagulation system was indicated as an additional factor for the threat of intravascular clotting.

Anticoagulant system. PC is the major anticoagulant proenzyme of the coagulation system. Being activated by the thrombin-thrombomodulin

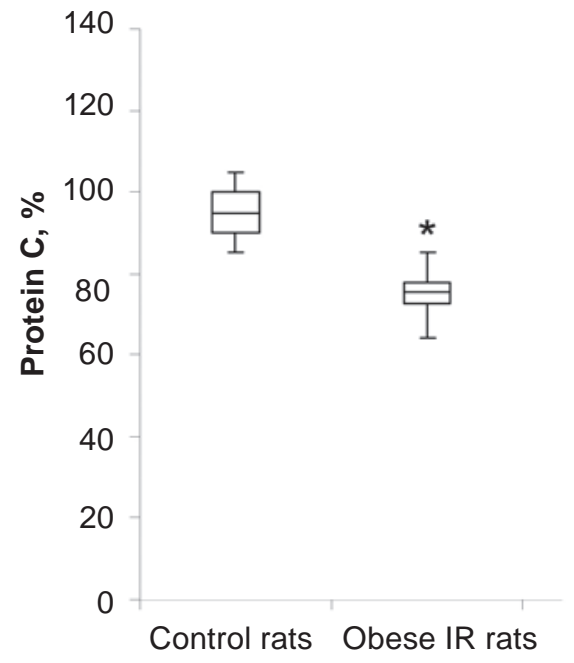

Fig. 3. Level of crucial anticoagulant factor - protein $C$ in blood plasma of control rats and obese insulin-resistant rats. The total protein C level was measured using non-physiological activating enzyme from the venom of Agkistrodon halys halys (APC) and protein C-specific chromogenic peptide substrate S2236 ( $p$-Glu-Pro-Arg-pNa). ( $p=0.0026$ according to Mann-Whitney U Test). *Statistically significant difference of means compared to control group, $P<0.05$ 

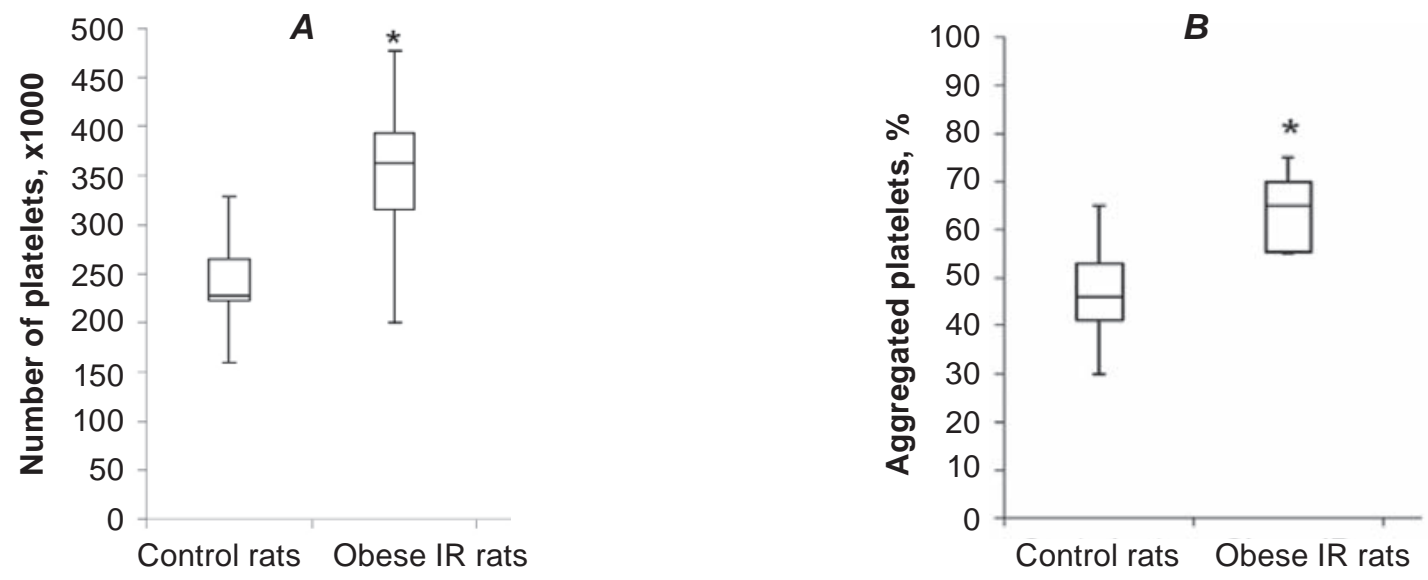

Fig. 4. Platelet count and reactivity in platelet rich blood plasma of control rats and obese insulin-resistant rats. A. Number of platelets in platelet-rich plasma (PRP) calculated using Aggregometer Solar 2110 ( $p=0.018$ according to Mann-Whitney U Test). B. Aggregation rate of platelets calculated according to final turbidity of PRP. Platelets were activated by $12.5 \mu \mathrm{M}$ of ADP ( $p=0.0072$ according to Mann-Whitney U Test). *Statistically significant difference of means compared to control group, $P<0.05$

complex, activated protein C (aPC) inactivates coagulation factors VIIIa and Va, reducing thrombin generation. On the other hand, aPC cleaves PAR-1 receptors of cells providing the anti-inflammatory and anti-apoptotic action [36]. So the decrease of PC level observed in blood plasma of obese IR rats most likely was the consequence of continual consumption of this enzyme caused by sporadic thrombin generation or low-grade inflammation.

And a drop in the PC level in blood plasma of obese IR rats was indeed observed (Fig. 3). All studied animals had decreased level of PC in blood plasma, in 2/3 of obese IR rats the level of PC decreased below $70 \%$, thus showing its overuse [37]. Taking into consideration the results of PT and APTT tests we can speculate that PC in blood plasma of obese diabetic rats was expended in order to compensate the pre-activation of the blood coagulation system. On the other hand, the decrease of PC level as the consequence of inflammation corresponds to the data showing increased fibrinogen level.

Platelet reactivity. Platelets are another hypersensitive component of haemostasis. The count and functional state of platelets can be altered in different pathologies [38]. In our studies we observed a prominent increase in platelet count (thrombocytosis) and the rate of platelet aggregation (Fig. 4) in the group of obese IR rats. Both these changes indicate the increased pro-coagulant potential of the haemostasis system and the risk of intravascular clotting. The increased platelet count is also evidence of chronic inflammation [39].
Histology: wall thickening and integrity changes of aorta. Thickening of the aortic wall is known as an important factor of atherogenesis in humans [40, 41]. The increased thickness of the aortic wall is a signal of developing atherosclerosis and the risk of intravascular coagulation [42, 43]. It is reported that intima-media thickness correlates significantly with coronary atherosclerosis [44].

As for rat models, modeled chronic hypertension provoked the thickening of rat aorta up to $15 \%$ [45]. The aorta of spontaneously hypertensive rats

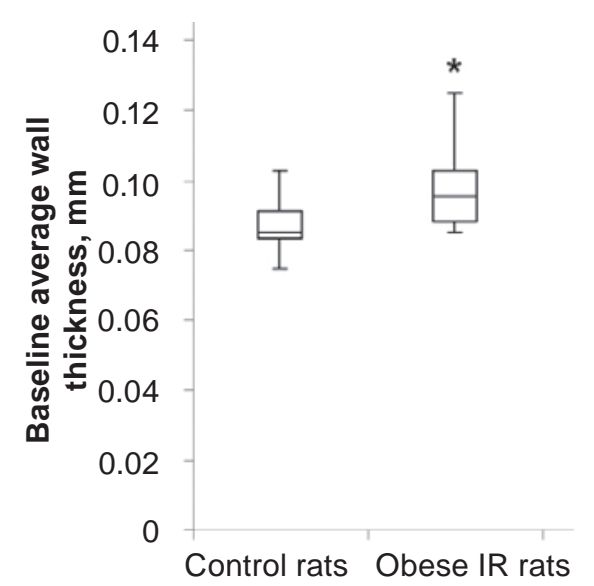

Fig. 5 Mean aortic wall thickness. Visualized through hematoxylin staining according to Ehrlich and calculated using ImageJ ( $p=0.01$ according to Mann-Whitney U Test). *Statistically significant difference of means compared to control group, $P<0.05$ 

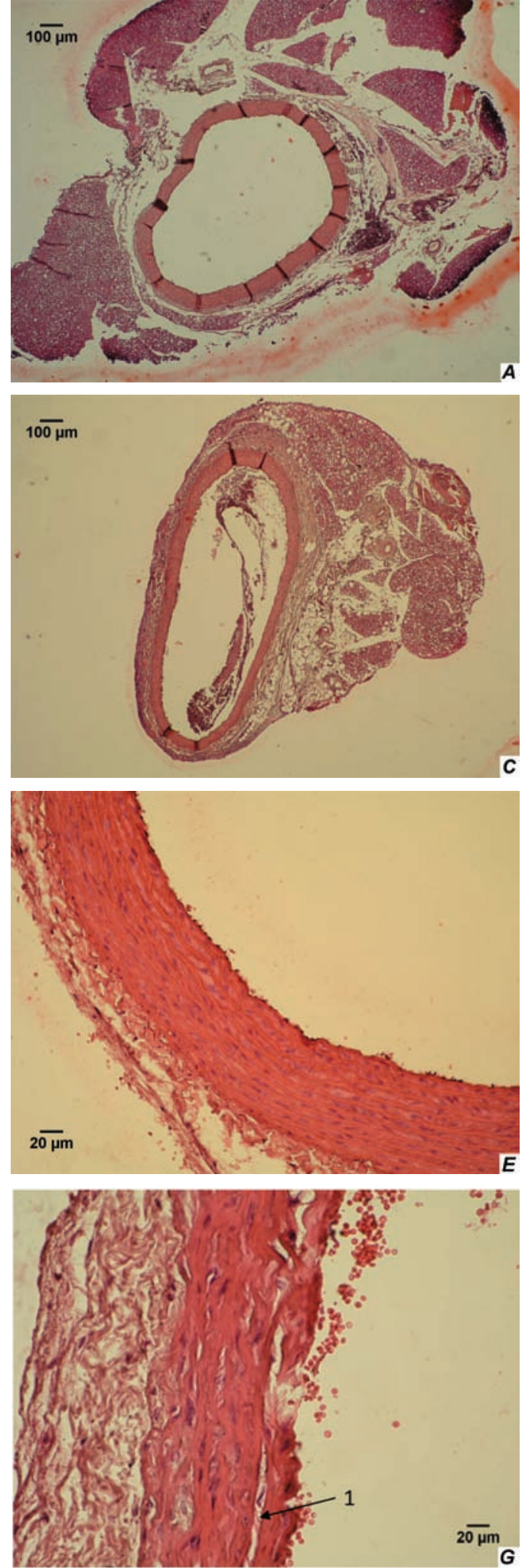
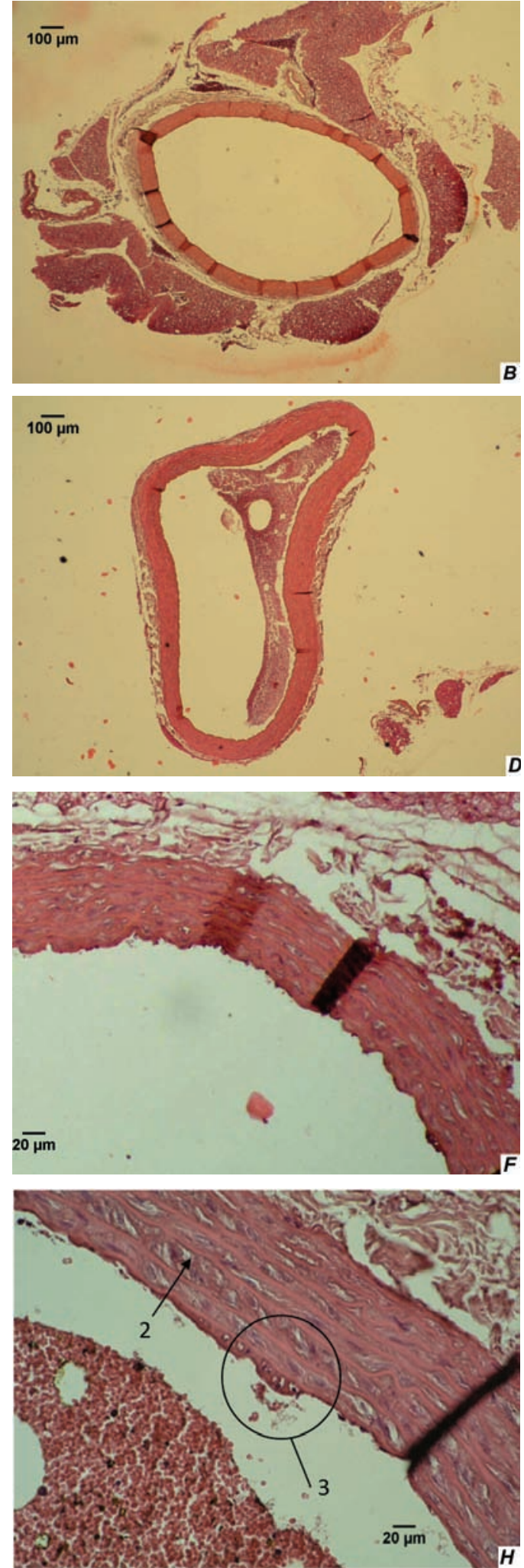

Fig. 6 Representative sections of aorta stained with hematoxylin according to Ehrlich. Control - a fragment of the aorta wall of a control rat $(\boldsymbol{A}, \boldsymbol{B}, \boldsymbol{E}, \boldsymbol{F})$. The integrity of the aortic wall of control rats is not disrupted; endothelium forms a monolayer; the middle layer is compactly arranged; outer shell is not thickened. IR $-a$ fragment of the aorta wall of an obese IR rat $(\boldsymbol{C}, \boldsymbol{D}, \boldsymbol{G}, \boldsymbol{H})$. Disruption of the middle shell of the aorta (1), edema of the middle layer of the aorta (2), swelling and detachment of the endothelial cells from the arteriolar wall, disturbance of the integrity of aortic endothelium (3) 
can be further thickened under the action of other chemical or biological agents [46, 47]. Thus, we did not expect prominent thickening of the aorta in the developed model of obese IR rats. However, calculation of the series of sections demonstrated the clear tendency for the thickening of the aorta in the group of obese IR rats compared to the group of control rats (Fig. 5).

The weak significance of these results could be explained by the small number of samples and the limitations of methods that we used. However, analysis of individual sections allowed us to identify the obvious signs of the disruptions in the aorta of obese IR rats (Fig. 6).

As shown on Fig. 6, endothelial cells form a monolayer in control samples of aorta. In the middle shell, the homogeneous and fibrous layers of the mixed membranes adhered closely to the windowlike elastic membranes. Also no changes were detected in the outer shell (Fig. 6, $A-B, E-F$ ).

In the same time, in the aorta of diabetic rats several changes in the integrity of the endothelial lining, swelling and detachment of endothelial cells were identified (Fig. 6, C-D, G-H). We also noted edema of the subendothelial layer and a disruption of the middle shell integrity. An increasing distance between the layers of window-like membranes indicated the edema development as well.

Thus, diet-induced obesity led to alterations in haemostasis and aorta morphology. In particular we demonstrated the increased coagulability and platelet over-reactivity in blood samples of obese insulinresistant rats. Decreased level of PC along with the tendency for increased fibrinogen concentration in blood plasma of obese IR rats was a consequence of instant low-grade inflammation and moderate thrombin-generation. The tendency for thickening of the aorta of obese insulin-resistant rats was also detected. Along with the demonstrated activation of the blood coagulation system, changes in the aorta wall could be a risk factor for the development of cardiovascular complications in obese IR animals.

\section{Acknowledgement}

We thank Cedars - Sinai Medical Center International Research and Innovation in Medicine Program, the Association for Regional Cooperation in the Fields of Health, Science and Technology (RECOOP HST Association) for their support of our organization as participating Cedars - Sinai Medical Center - RECOOP Research Centres (CRRC).
This work was partially supported by the research grant for young scientists of the National Academy of Sciences of Ukraine "Neurodegenerative, inflammatory and thrombogenic process at atherosclerosis in vivo" - 0177U003559.

\section{References}

1. Opara JU, Levine JH. The deadly quartet-the insulin resistance syndrome. South Med J. 1997; 90(12): 1162-1168.

2. Han TS, Lean ME. A clinical perspective of obesity, metabolic syndrome and cardiovascular disease. JRSM Cardiovasc Dis. 2016; 5: 1-13.

3. Libby P, Ridker PM, Maseri A. Inflammation and atherosclerosis. Circulation. 2002; 105(9): 1135-1143.

4. Ross R. Cell biology of atherosclerosis. Annu Rev Physiol. 1995; 57: 791-804.

5. Bennett MR. The atherosclerotic plaque was not built in a day: the dynamic nature of plaque progression and instability. Heart Metab. 2007; 36: 5-7.

6. Bergmeier W, Hynes RO. Extracellular matrix proteins in hemostasis and thrombosis. Cold Spring Harb Perspect Biol. 2012; 4(2): a005132.

7. Wang Y, Gallant RC, Ni H. Extracellular matrix proteins in the regulation of thrombus formation. Curr Opin Hematol. 2016; 23(3): 280-287.

8. Watson SP. Platelet activation by extracellular matrix proteins in haemostasis and thrombosis. Curr Pharm Des. 2009; 15(12): 1358-1372.

9. Thompson WD, Smith EB. Atherosclerosis and the coagulation system. J Pathol. 1989; 159(2): 97-106.

10. Wong AP, Mohamed AL, Niedzwiecki A. Atherosclerosis and the Cholesterol Theory: A Reappraisal. World J Cardiovasc Dis. 2016; 6(11): 391-409.

11. Berliner JA, Navab M, Fogelman AM, Frank JS, Demer LL, Edwards PA, Watson AD, Lusis AJ. Atherosclerosis: basic mechanisms. Oxidation, inflammation, and genetics. Circulation. 1995; 91(9): 2488-2496.

12. Ravnskov $U$. The fallacies of the lipid hypothesis. Scand Cardiovasc J. 2008; 42(4): 236-239.

13. Ware WR. The mainstream hypothesis that LDL cholesterol drives atherosclerosis may have been falsified by non-invasive imaging of coronary artery plaque burden and progression. Med Hypotheses. 2009; 73(4): 596-600. 
14. Rosch PJ. Cholesterol does not cause coronary heart disease in contrast to stress. Scand Cardiovasc J. 2008; 42(4): 244-249.

15. Borissoff JI, Spronk HM, ten Cate H. The hemostatic system as a modulator of atherosclerosis. $N$ Engl $J$ Med. 2011; 364(18): 1746-1760.

16. Borissoff JI, Heeneman S, Kilinç E, Kassák P, Van Oerle R, Winckers K, Govers-Riemslag JW, Hamulyák K, Hackeng TM, Daemen MJ, ten Cate H, Spronk HM. Early atherosclerosis exhibits an enhanced procoagulant state. Circulation. 2010; 122(8): 821-830.

17. Ten Cate H, Hemker HC. Thrombin Generation and Atherothrombosis: What Does the Evidence Indicate? J Am Heart Assoc. 2016; 5(8). pii: e003553.

18. Kalz J, ten Cate H, Spronk HM. Thrombin generation and atherosclerosis. $J$ Thromb Thrombolysis. 2014; 37(1): 45-55.

19. Solovjov DA, Platonova TN, Ugarova TP. Purification and characterization of ecamulin a new prothrombin activator from the Echis multisquamatus snake venom. Biochemistry (Mosc). 1996; 61(6): 785-793.

20. Collier GR, Chisholm K, Sykes S, Dryden PA, O'Dea K. More severe impairment of oral than intravenous glucose tolerance in rats after eating a high fat diet. J Nutr. 1985; 115(11): 1471-1476.

21. Gryshchuk V, Galagan N. Silica Nanoparticles Effects on Blood Coagulation Proteins and Platelets. Biochem Res Int. 2016;2016:2959414.

22. Korolova D, Chernyshenko V, Platonova T, Chernyshenko T, Lugovskoy E. Detection of Prethrombin 1 in Human Blood Plasma. Int Blood Res Rev. 2016; 5(2): 1-7.

23. Hryshchenko VA, Tomchuk VA, Lytvynenko OM, Chernyshenko VO, Hryshchuk VI, Platonova TM. Assessment of protein synthesizing function of the liver in experimental hepatitis. Ukr Biokhim Zhurn. 2011; 83(1): 6368. (In Ukrainian).

24. Gornitskaia OV, Platonova TN. Isolation and properties of the protein $\mathrm{C}$ activator from Agkistrodon halys halys venom. Biomed Khim. 2003; 49(5): 470-478. (In Russian).

25. Cattaneo M, Cerletti C, Harrison P, Hayward CP, Kenny D, Nugent D, Nurden P, Rao AK, Schmaier AH, Watson SP, Lussana F, Pugliano MT, Michelson AD. Recommendations for the standardization of light transmission aggregometry: a consensus of the working party from the platelet physiology subcommittee of SSC/ISTH. J Thromb Haemost. 2013; 11: 11831189.

26. Tulis DA. Histological and morphometric analyses for rat carotid balloon injury model. Methods Mol Med. 2007; 139: 31-66.

27. Onopchenko OV, Kosiakova GV, Goridko TM, Klimashevsky VM, Hula NM. The effect of $\mathrm{N}$-stearoylethanolamine on liver phospholipid composition of rats with insulin resistance caused by alimentary obesity. Ukr Biochem $J$. 2014; 86(1): 101-110. (In Ukrainian).

28. Onopchenko OV, Kosiakova GV, Klimashevsky VM, Hula NM. The effect of $\mathrm{N}$-stearoylethanolamine on plasma lipid composition in rats with experimental insulin resistance. Ukr Biochem J. 2015; 87(1): 46-54.

29. Palta S, Saroa R, Palta A.Overview of the coagulation system. Indian $J$ Anaesth. 2014;58(5): 515-523.

30. Chandrashekar V. DIC Score: Statistical Relationship with PT, APTT, and Simplified Scoring Systems with Combinations of PT and APTT. ISRN Hematol. 2012; 2012: 579420.

31. Platonova TM, Chernyshenko TM, Hornyts'ka OV, Savchuk OM, Sokolovs'ka LI, Hamisoniia MSh, Makohonenko IeM. Laboratory diagnosis of the status of the hemostasis system. Ukr Biokhim Zhurn. 2000; 72(6): 67-73. (In Ukrainian).

32. Roshal M. Prothrombin Time. Transfusion Medicine and Hemostasis (Second Edition). Clinical and Laboratory Aspects. 2013; Chapt. 124: 799-803.

33. Lippi G, Salvagno GL, Ippolito L, Franchini M, Favaloro EJ. Shortened activated partial thromboplastin time: causes and management. Blood Coagul Fibrinolysis. 2010; 21(5): 459-463.

34. Volkov GL, Platonova TN, Savchuk AN, Gornitskaya OV, Chernyshenko TM, Krasnobryzhaya EN. Modern conceptions of hemostasis system. Kiev: Naukova dumka, 2005; 296 p.

35. Davalos D, Akassoglou K. Fibrinogen as a key regulator of inflammation in disease. Semin Immunopathol. 2012; 34(1): 43-62.

36. Bouwens EA, Stavenuiter F, Mosnier LO. Mechanisms of anticoagulant and cytoprotective actions of the protein C pathway. J Thromb Haemost. 2013; 11(Suppl 1): 242-253. 
37. Ena IaM, Platonova TN, Sushko EA, Solov'ev DA, Usichenko TI. The biological role and clinical significance of protein C. Lik Sprava. 1992;(6): 20-25. (In Russian).

38. Ghoshal K, Bhattacharyya M. Overview of platelet physiology: its hemostatic and nonhemostatic role in disease pathogenesis. Sci World J. 2014; 2014: 781857.

39. Hasselbalch HC. Perspectives on chronic inflammation in essential thrombocythemia, polycythemia vera, and myelofibrosis: is chronic inflammation a trigger and driver of clonal evolution and development of accelerated atherosclerosis and second cancer? Blood. 2012; 119(14): 3219-3225.

40. Biancari F, Lahtinen J, Heikkinen J. Impact of ascending aortic wall thickness and atherosclerosis on the intermediate survival after coronary artery bypass surgery. Eur $J$ Cardiothorac Surg. 2012; 41(5): e94-e99.

41. Schachner T, Nagele G, Kacani A, Laufer G, Bonatti J. Factors associated with presence of ascending aortic atherosclerosis in CABG patients. Ann Thorac Surg. 2004; 78(6): 20282032.

42. Laurent S, Boutouyrie P, Asmar R, Gautier I, Laloux B, Guize L, Ducimetiere P, Benetos A. Aortic stiffness is an independent predictor of all-cause and cardiovascular mortality in hypertensive patients. Hypertension. 2001; 37(5): 1236-1241.

43. Amarenco P, Cohen A, Tzourio C, Bertrand B, Hommel M, Besson G, Chauvel C, Touboul PJ, Bousser MG. Atherosclerotic disease of the aortic arch and the risk of ischemic stroke. N Engl J Med. 1994; 331(22): 1474-1479.

44. Bae JH, Bassenge E, Park KR, Kim KY, Schwemmer M. Significance of the intimamedia thickness of the thoracic aorta in patients with coronary atherosclerosis. Clin Cardiol. 2003; 26(12): 574-578.

45. He Z, Vingrys AJ, Armitage JA, Nguyen CT, Bui BV. Chronic hypertension increases susceptibility to acute IOP challenge in rats. Invest Ophthalmol Vis Sci. 2014; 55(12): 78887895.

46. Watts SW, Rondelli C, Thakali K, Li X, Uhal B, Pervaiz MH, Watson RE, Fink GD. Morphological and biochemical characterization of remodeling in aorta and vena cava of DOCAsalt hypertensive rats. Am J Physiol Heart Circ Physiol. 2007 May;292(5):H2438-48.

47. Li P, Huang PP, Yang Y, Liu C, Lu Y, Wang F, Sun W, Kong XQ. Renal sympathetic denervation attenuates hypertension and vascular remodeling in renovascular hypertensive rats. J Appl Physiol (1985). 2017 Jan 1;122(1):121-129.

Received 21.03.2018 